\title{
Composição química e digestibilidade da matéria seca do bagaço de cana-de-açúcar tratado com óxido de cálcio
}

[Chemical composition and dry matter digestibility of sugarcane bagasse treated with calcium oxide]

\author{
G.G.P. Carvalho ${ }^{1}$, J. Cavali ${ }^{1}$, F.E.P. Fernandes ${ }^{1}$, L.O. Rosa $^{2}$, C.S. Olivindo ${ }^{1}$, M.O. Porto ${ }^{1}$, \\ A.J.V.Pires ${ }^{3,5}$, R. Garcia ${ }^{4,5}$ \\ ${ }^{1}$ Aluno de pós-graduação - UFV - Viçosa, MG (Bolsista do CNPq) \\ ${ }^{2}$ Aluna de graduação - UFV - Viçosa, MG (Bolsista IC-CNPq) \\ ${ }^{3}$ Universidade Estadual do Sudoeste da Bahia - Itapetinga, BA \\ ${ }^{4}$ Departamento de Zootecnia - UFV - Viçosa, MG \\ ${ }^{5}$ Pesquisador do $\mathrm{CNPq}$
}

\begin{abstract}
RESUMO
Avaliaram-se a composição química e a digestibilidade in vitro da matéria seca (DIVMS) do bagaço de cana-de-açúcar hidrolisado com óxido de cálcio em dois períodos. As doses de óxido de cálcio aplicadas ao bagaço foram $0 ; 1,25 ; 2,5$ e $3,75 \%$ (na base da MS) e os períodos de tratamento, 12 e 36 horas. O teor de matéria seca (MS) do bagaço de cana foi maior quando hidrolisado por 36 horas. O valor médio da proteína bruta foi de $2,4 \%$ e não foi influenciado pelo período, pela dose de óxido de cálcio nem pela interação período $\times$ dose de óxido de cálcio. Os teores de fibra em detergente neutro, fibra em detergente ácido, celulose e lignina diminuíram linearmente com a adição de óxido de cálcio. A digestibilidade in vitro da matéria seca, no entanto, aumentou $1,2 \%$ a cada unidade de óxido de cálcio adicionada ao bagaço da cana-de-açúcar. O tratamento com óxido de cálcio por 12 ou 36 horas melhora o valor nutritivo do bagaço de cana-de-açúcar.
\end{abstract}

Palavras-chave: bagaço, cana-de-açúcar, parede celular, tratamento químico, valor nutritivo

\begin{abstract}
The chemical composition and in vitro dry matter digestibility (IVDMD) of sugarcane bagasse hydrolyzed with calcium oxide ( $\mathrm{CaO})$ in two periods were evaluated. The doses of calcium oxide applied to bagasse were $0 ; 1.25 ; 2.5$; and 3.75\% (dry matter basis) and the treatment periods were 12 and 36 hours. The dry matter sugarcane bagasse was larger when hydrolyzed for 36 hours. The crude protein mean value observed was $2.4 \%$, with no effects of period, CaO doses, or period and CaO interaction. The neutral detergent fiber, acid detergent fiber, celluloses, and lignin levels linearly reduced with $\mathrm{CaO}$ added. The IVDMD increased with $\mathrm{CaO}$ add, estimating increase of $1.2 \%$ for each $\mathrm{CaO}$ unit added to sugarcane bagasse. The periods of 12 or 36 hours can be adopted to sugarcane bagasse treatment with $\mathrm{CaO}$. The $\mathrm{CaO}$ addiction to sugarcane bagasse improve its nutritive value.
\end{abstract}

Keywords: bagasse, sugarcane, cellular wall, chemical treatment, nutritive value

\section{INTRODUÇÃO}

A sazonalidade de produção forrageira é um dos principais entraves na produção animal. Nesse sentido, a busca por alternativas alimentares, como os resíduos e subprodutos da agroindústria, tem grande importância no sistema de alimentação de ruminantes.

O bagaço de cana constitui uma fonte alimentar promissora para ruminantes, uma vez que o período de safra da cana coincide com o período

Recebido em 24 de novembro de 2008

Aceito em 30 de setembro de 2009

E-mail: gleidsongiordano@gmail.com 
de escassez de alimentos volumosos, em várias regiões do Brasil. Apesar do potencial para suprir parte das exigências dos animais, sobretudo no período da seca, normalmente, o valor nutritivo do bagaço de cana é baixo, pois esse alimento possui baixo teor de proteína e minerais e elevado teor de fibra (Prado e Moreira, 2002).

Uma opção para melhorar o valor nutritivo de alimentos volumosos com elevado teor de fibra é o tratamento químico. Carvalho et al. (2006) avaliaram o uso de $0,2,5 ; 5,0$ e 7,5\% de ureia no tratamento do bagaço de cana-de-açúcar e verificaram aumento de 3,$7 ; 6,9 ; 9,9$ e $12,9 \%$ nos teores de proteína bruta (PB) e redução de 78,1 ; 71,$3 ; 64,4$ e $57,6 \%$ nos teores de fibra em detergente neutro (FDN), respectivamente, em porcentagem da matéria seca. Esses autores observaram, ainda, aumento de 15,9 unidades percentuais na digestibilidade in vitro da matéria seca no bagaço tratado com $7,5 \%$ de ureia. Pires et al. (2004) testaram a viabilidade do uso de produtos químicos em volumosos de baixa qualidade e verificaram aumento de 32,1 e $59,8 \%$, respectivamente, na digestibilidade in vitro da matéria seca do bagaço de cana-deaçúcar sem tratamento com $\mathrm{NH}_{3}$ e tratado com $4 \%$ de $\mathrm{NH}_{3}$.

Outro aditivo bastante utilizado no tratamento de volumosos é o óxido de cálcio $(\mathrm{CaO})$, na forma de cal microprocessada ou micropulverizada, um produto de origem mineral, que passa por um processo industrial e adquire aparência de matéria refinada (Martines, 2006). Balieiro Neto et al. (2007) observaram redução do teor de FDN e aumento expressivo na digestibilidade in vitro da matéria seca da cana-de-açúcar tratada com óxido de cálcio no momento da ensilagem.

Este trabalho foi conduzido com o objetivo de avaliar a composição química e a digestibilidade in vitro da matéria seca do bagaço de cana-deaçúcar tratado com óxido de cálcio durante dois períodos.

\section{MATERIAL E MÉTODOS}

O experimento foi realizado em esquema fatorial $2 \times 4$, composto de dois períodos de tratamento (12 ou 36 horas) e quatro doses de óxido de cálcio, $0 ; 1,25 ; 2,5$ ou $3,75 \%$, com base na matéria seca, cada uma com quatro repetições.
O bagaço de cana-de-açúcar utilizado foi adquirido em feira livre localizada no município de Viçosa, Minas Gerais. Antes da adição de óxido cálcio, uma amostra do bagaço foi coletada para avaliação da composição química desse alimento, que apresentou $40 \%$ de matéria seca, $2,4 \%$ de proteína bruta, $63 \%$ de fibra em detergente neutro, $50 \%$ de digestibilidade in vitro da matéria seca.

Em cada dose e período de avaliação, o óxido de cálcio foi adicionado, a $3 \mathrm{~kg}$ de bagaço de canade-açúcar, previamente desintegrado em desintegrador estacionário. Depois de misturado, o material foi homogeneizado e armazenado em galpão coberto. Amostras do bagaço acrescido de óxido de cálcio foram coletadas em dois períodos (12 e 36 horas), em cada unidade experimental, acondicionadas em sacos plásticos e armazenadas em freezer para posterior análise. $\mathrm{O}$ material foi pré-seco em estufa a $60^{\circ} \mathrm{C}$, por 72 horas, e triturado em moinho tipo Willey com peneira de $1 \mathrm{~mm}$. As amostras foram acondicionadas em embalagens plásticas, identificadas e armazenadas em local fresco para posterior análise química e determinação dos teores de proteína bruta (PB), fibra em detergente neutro (FDN), fibra em detergente ácido (FDA), celulose, lignina e hemicelulose, e da digestibilidade in vitro da matéria seca (DIVMS), segundo procedimentos descritos por Silva e Queiroz (2002).

Os resultados foram submetidos à análise de variância, procedendo-se à decomposição ortogonal da soma de quadrados de tratamentos em efeitos de ordem linear, quadrática e cúbica, com posterior ajuste de regressões lineares. Todos os procedimentos estatísticos foram realizados com o auxílio do programa SAEG (Sistema..., 2001), adotando-se 1\% como nível crítico de probabilidade.

\section{RESULTADOS E DISCUSSÃO}

Não se verificou efeito de adição de óxido de cálcio ao bagaço nem da interação óxido de cálcio $\times$ período de tratamento sobre o teor de matéria seca do bagaço de cana-de-açúcar. O período de tratamento, no entanto, influenciou o teor de matéria seca do bagaço de cana-deaçúcar, cujos valores foram de 39,3 e 45,8\%, respectivamente, nos períodos 12 e 36 horas de tratamento (Tab. 1). O armazenamento em 
galpão coberto, exposto ao ar, portanto, à desidratação constante, elevou o teor de matéria seca do material. Os resultados observados neste estudo confirmam informações de Pires et al. (1999) e Sarmento et al. (1999), respectivamente, que observaram aumento do teor de matéria seca da quirera de milho com alto teor de umidade e do bagaço de cana conforme aumentaram os períodos de areação.

Os teores de proteína bruta do bagaço de cana não foram afetados pelo período de tratamento, pela adição de óxido de cálcio nem pela interação período $\times$ doses de óxido de cálcio e mantiveram-se próximos, variando entre 2,3 e $2,5 \%$. O teor de proteína bruta em material tratado tem sido frequentemente elevado pelo uso de aditivos químicos, como a ureia e amônia anidra, que possuem elevado teor de nitrogênio não-proteico. Carvalho et al. (2006) avaliaram o valor nutritivo do bagaço de cana-de-açúcar tratado com $0 ; 2,5 ; 5,0$ ou $7,5 \%$ de ureia, na matéria seca, e verificaram aumento linear do teor de proteína bruta, com valores de 3,9; 6,9; 9,9 e $13,0 \%$. No entanto, os resultados obtidos neste trabalho foram próximos aos observados por Balieiro Neto et al. (2007), que aplicaram quatro doses de óxido de cálcio $(0,0 ; 0,5 ; 1,0$ e $2,0 \%$ da matéria original) à cana-de-açúcar e não notaram efeito desse aditivo nos teores de proteína bruta.

Tabela 1. Médias de quadrados mínimos e coeficiente de variação (CV) obtidos para os teores de matéria seca (MS), proteína bruta (PB), fibra em detergente neutro (FDN), fibra em detergente ácido (FDA), hemicelulose, celulose, lignina e digestibilidade in vitro da matéria seca (DIVMS) do bagaço de cana-deaçúcar em função do período de tratamento, doses de óxido de cálcio $(\mathrm{CaO})$ e interação período de tratamento versus dose de óxido de cálcio $(\mathrm{CaO})$

\begin{tabular}{|c|c|c|c|c|c|c|c|c|c|c|}
\hline \multirow[t]{2}{*}{ Item } & \multicolumn{2}{|c|}{$\begin{array}{c}\text { Período } \\
\text { (horas) }\end{array}$} & \multicolumn{4}{|c|}{ Dose de $\mathrm{CaO}(\% \mathrm{MS})$} & \multicolumn{3}{|c|}{ Efeito } & \multirow[t]{2}{*}{$\begin{array}{l}\text { CV } \\
(\%)\end{array}$} \\
\hline & 12 & 36 & 0 & 1,25 & 2,5 & 3,75 & Período & $\mathrm{CaO}$ & $\begin{array}{c}\text { Período } \\
\times \mathrm{CaO}\end{array}$ & \\
\hline MS & 39,3 & 45,8 & 41,7 & 42,3 & 42,3 & 43,7 & $<0,0001$ & ns & $\mathrm{ns}$ & 3,1 \\
\hline PB & 2,4 & 2,4 & 2,4 & 2,3 & 2,5 & 2,4 & ns & ns & ns & 6,9 \\
\hline FDN & 59,3 & 61,4 & 63,3 & 61,6 & 59,7 & 56,6 & ns & $<0,0001$ & ns & 2,0 \\
\hline FDA & 50,9 & 53,0 & 54,8 & 53,3 & 51,5 & 49,2 & ns & $<0,0001$ & ns & 3,2 \\
\hline Hemicelulose & 8,4 & 8,4 & 8,5 & 8,4 & 8,2 & 8,4 & $\mathrm{~ns}$ & ns & ns & 17,7 \\
\hline Celulose & 44,4 & 45,8 & 47,2 & 47,4 & 44,2 & 41,5 & ns & $<0,0001$ & $\mathrm{~ns}$ & 3,4 \\
\hline Lignina & 6,5 & 7,2 & 7,6 & 5,9 & 7,3 & 6,7 & $\mathrm{~ns}$ & ns & $\mathrm{ns}$ & 7,6 \\
\hline DIVMS & 52,8 & 52,3 & 50,1 & 52,6 & 52,4 & 55,4 & ns & 0,0002 & ns & 3,4 \\
\hline
\end{tabular}

ns = não-significativo $(\mathrm{P}>0,01)$.

Quanto aos teores de fibra em detergente neutro (FDN), fibra em detergente ácido (FDA) e celulose, houve efeito da dose de óxido de cálcio, isto é, os teores diminuíram linearmente conforme aumentaram as doses de óxido de cálcio no bagaço de cana-de-açúcar (Fig. 1, 2 e 3, respectivamente), o que pode ser explicado pela ocorrência de hidrólise alcalina e solubilização de componentes da parede celular.

Cavali (2006) observou redução dos teores de FDN, FDA e celulose da silagem cana-de-açúcar tratada com $0 ; 0,5 ; 1 ; 1,5$ e $2 \%$ de óxido de cálcio ( $\%$ da matéria original). Os resultados encontrados neste trabalho também foram semelhantes aos registrados por Balieiro Neto et al. (2007), que aplicaram óxido de cálcio $(0,0$; 0,$5 ; 1,0$ e $2,0 \%$ da matéria original) à cana-de- açúcar e observaram redução nos teores de FDN, e por Ferreira et al. (2007), que também observaram redução no teor de FDN na cana-deaçúcar tratada com $0,5 \%$ de ureia (\% da matéria natural) após 28 dias de ensilagem. Campos et al. (2003) relataram que o uso de aditivos, como o hidróxido de sódio $(\mathrm{NaOH})$, o óxido de cálcio e a ureia, promove ruptura das estruturas lignocelulósicas, como resultado da hidrólise alcalina, uma vez que a celulose é passível de ser hidrolisada a hexoses e a hemicelulose, a pentoses. Neste estudo, composição em lignina do bagaço de cana não foi influenciada pela adição do óxido de cálcio, contudo os resultados obtidos evidenciam a ação marcante da hidrólise alcalina sobre os componentes da parede celular, especialmente celulose, promovendo efeitos diretos no teor de fibra do material. 


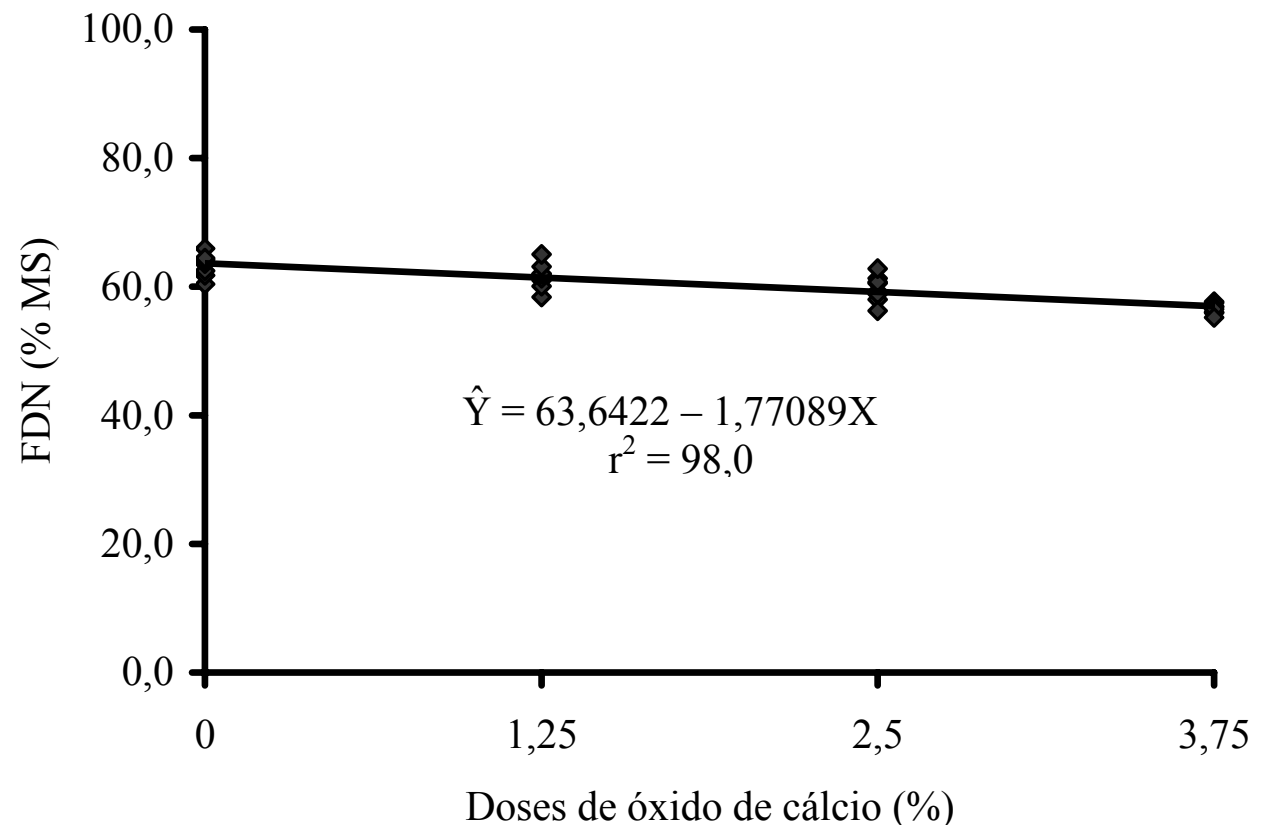

Figura 1. Estimativa dos teores de fibra em detergente neutro (FDN) do bagaço de cana-de-açúcar tratado com óxido de cálcio

** Significativo a $1 \%$ de probabilidade pelo teste $\mathrm{F}$.

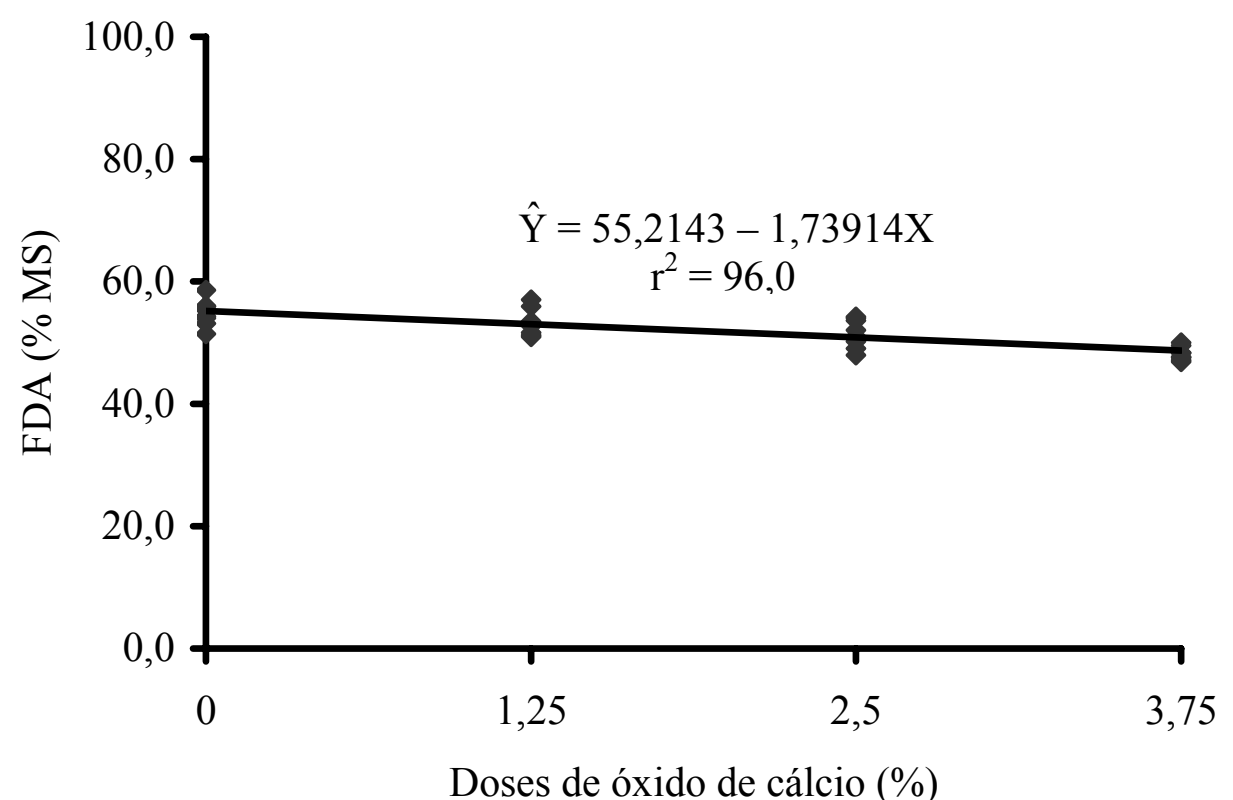

Figura 2. Estimativa dos teores de fibra em detergente ácido (FDA) do bagaço de cana-de-açúcar tratado com óxido de cálcio.

** Significativo a $1 \%$ de probabilidade pelo teste $\mathrm{F}$. 


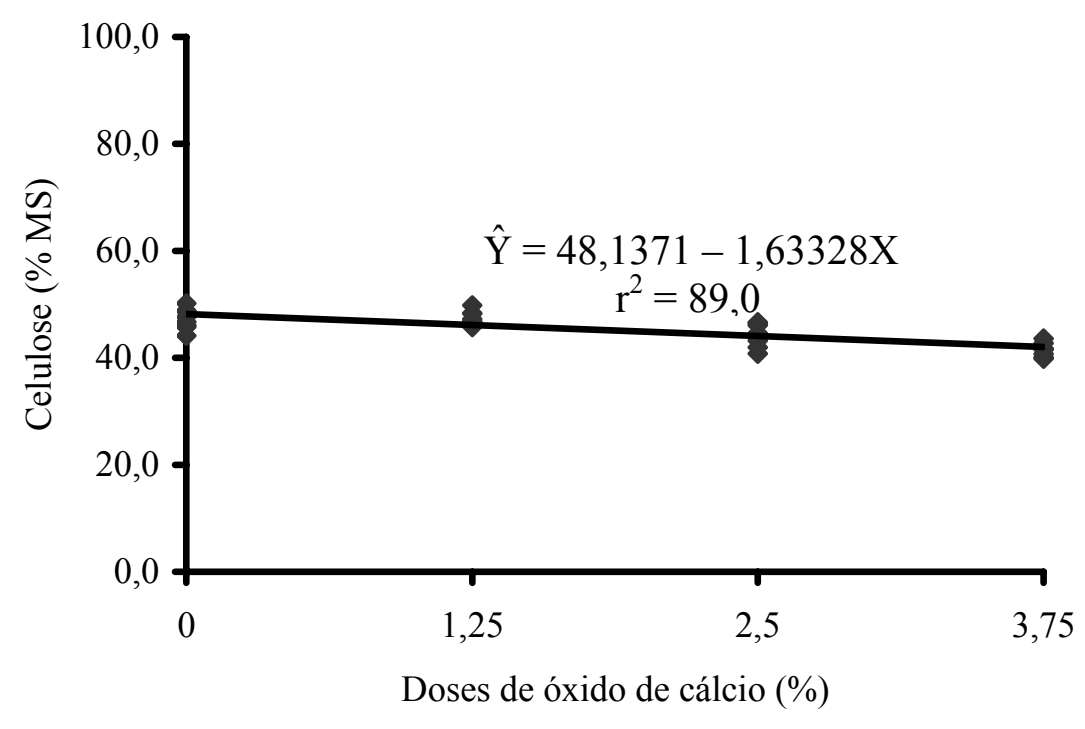

Figura 3. Estimativa dos teores de celulose do bagaço de cana-de-açúcar tratado com óxido de cálcio.

** Significativo a $1 \%$ de probabilidade pelo teste $\mathrm{F}$.

O banco de informações sobre a utilização de óxido de cálcio em volumosos ainda é incipiente, contudo as informações obtidas em pesquisas até o momento indicam que o $\mathrm{NaOH}$, em comparação ao óxido de cálcio, age com maior eficiência na parede celular de volumosos de baixa qualidade. Essa maior eficiência foi observada por Pires at al. (2006), que detectaram pronunciado efeito da hidrólise alcalina do $\mathrm{NaOH}$ sobre os componentes da parede celular, provocando redução inclusive da lignina com a inclusão de $0 ; 2,5 ; 5$ ou 7,5\% de $\mathrm{NaOH}$ (\%MS).

A digestibilidade in vitro da matéria seca (DIVMS) da cana-de-açúcar aumentou linearmente com a adição de óxido de cálcio (Fig. 4). Esse aumento da digestibilidade in vitro da matéria seca em materiais tratados com produtos alcalinos tem sido relatado na literatura (Carvalho et al., 2006; Cavali, 2006; Pires et al., 2006; Balieiro Neto et al., 2007) como resultado da hidrólise alcalina, rompendo ligações e causando expansão da celulose, o que aumenta a eficiência do ataque microbiano à parede celular, melhorando a digestibilidade.

Balieiro Neto et al. (2007) adicionaram 0,0; 0,5; 1,0 e $2,0 \%$ de óxido de cálcio (na matéria original) à cana-de-açúcar e observaram aumento na DIVMS, com valores de 62,$1 ; 65,6 ; 70,7$ e $79,2 \%$, respectivamente.

Os resultados observados neste trabalho confirmam os obtidos por Carvalho et al. (2006), que aplicaram doses crescentes de ureia ao bagaço de cana-de-açúcar e verificaram aumento linear na DIVMS, com valores de 33,0; 38,2; 43,5 e $48,8 \%$, respectivamente, para as doses 0 ; 2,$5 ; 5$ e $7,5 \%$ de ureia $(\% \mathrm{MS})$.

Estudos com outros produtos químicos também têm apresentado resultados promissores. Pires et al. (2004), ao estudarem doses de sulfeto de sódio $\left(\mathrm{Na}_{2} \mathrm{~S}\right)$ e amônia anidra $\left(\mathrm{NH}_{3}\right)$ no tratamento do bagaço de cana-de-açúcar, observaram que, independentemente da fonte de $\mathrm{Na}_{2} \mathrm{~S}$ aplicada, a presença de amônia anidra provocou aumento na DIVMS, que apresentou valores de 32,1; 32,9; 59,8 e 58,1\%, respectivamente, para os tratamentos controle, $2,5 \%$ de $\mathrm{Na}_{2} \mathrm{~S}, 4 \%$ de $\mathrm{NH}_{3}$ e $2,5 \%$ de $\mathrm{Na}_{2} \mathrm{~S}+4 \%$ de $\mathrm{NH}_{3}$ (\%MS). Aumento na DIVMS do bagaço de cana também foi evidenciado em trabalho realizado por Pires et al. (2006), que aplicaram doses crescentes de amônia anidra $(0 ; 2,5 ; 5$ e $7,5 \%$ da matéria seca) e registraram aumento linear na DIVMS do bagaço. 


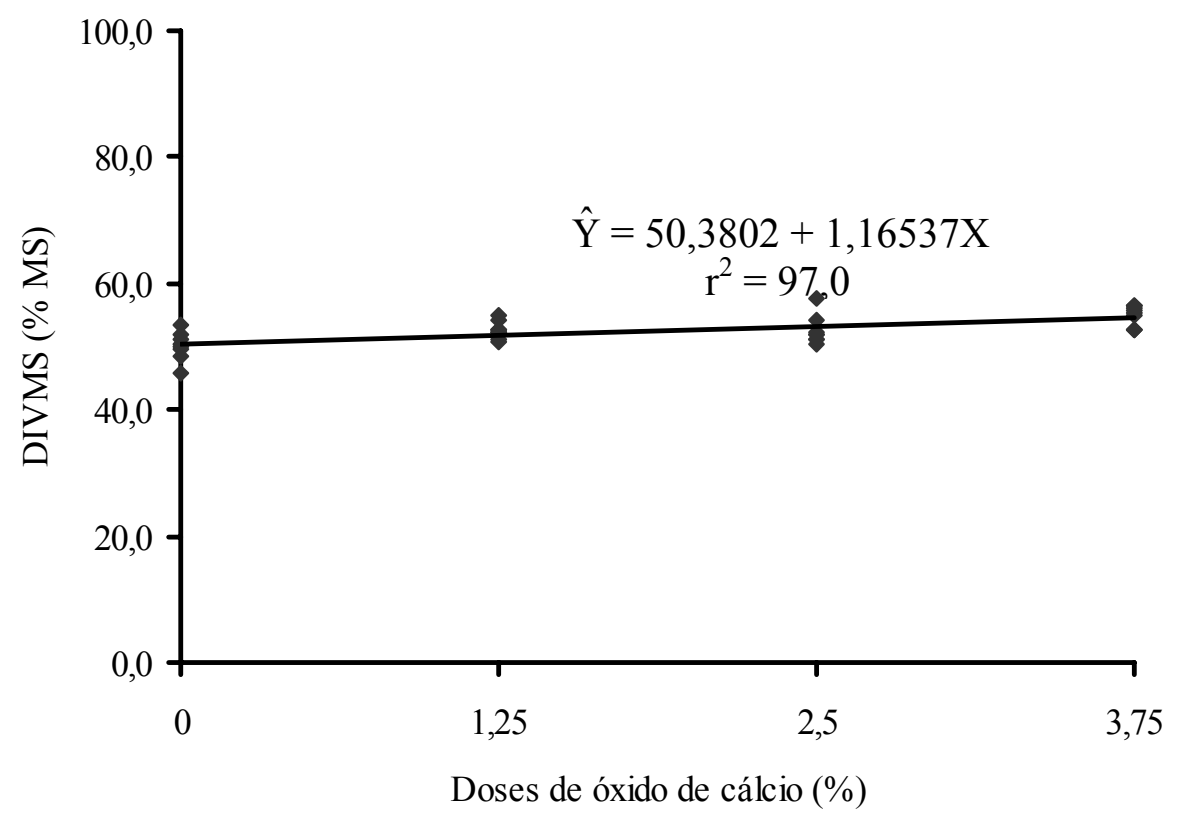

Figura 4. Estimativa da digestibilidade in vitro da matéria seca (DIVMS) do bagaço de cana-de-açúcar tratado com óxido de cálcio.

** Significativo a $1 \%$ de probabilidade pelo teste $\mathrm{F}$.

A melhoria na digestibilidade dos volumosos com a adição de aditivos alcalinos está relacionada à ação da hidrólise alcalina e constitui um grande benefício do ponto de vista nutricional, uma vez que, em um eventual sistema de alimentação, dietas balanceadas com volumosos tratados podem predispor animais a desempenhos semelhantes ao obtido com dietas de alta qualidade, balanceadas com volumosos como silagem de milho e sorgo. Essa hipótese foi confirmada por Cardoso et al. (2004), que observaram que dietas balanceadas com palhada de arroz tratada com $3 \%$ de $\mathrm{NH}_{3}$ (\%MS) promoveram ganho de peso semelhante $(1,59 \mathrm{~kg} / \mathrm{dia})$ ao obtido com dietas contendo silagem de sorgo como volumoso $(1,42 \mathrm{~kg} / \mathrm{dia})$. A dieta com a palhada tratada promoveu ganho de peso médio superior ao observado nos animais mantidos com a dieta com cana-de-açúcar corrigida com ureia como volumoso (apenas de $1,11 \mathrm{~kg} / \mathrm{dia})$.

\section{CONCLUSÕES}

Os períodos de tratamento de 12 ou 36 horas podem ser adotados no tratamento do bagaço de cana com óxido de cálcio, portanto a opção por um ou outro período depende do manejador. A adição de óxido de cálcio ao bagaço de cana-deaçúcar em doses de até $3,75 \%$ da matéria seca reduz os componentes da parede celular e aumenta a digestibilidade in vitro da matéria seca, podendo, assim, ser recomendada.

\section{REFERÊNCIAS BIBLIOGRÁFICAS}

BALIEIRO NETO, G.; SIQUEIRA, G. R.; REIS, R. A. et al. Óxido de cálcio como aditivo na ensilagem de cana-de-açúcar. Rev. Bras. Zootec., v.36, p.1231-1239, 2007.

CAMPOS, A.B.; BENEDETTI, E.; MARI, L.J. et al. Valor nutritivo de seis variedades de canade-açúcar tratadas com aditivos. In: REUNIÃO ANUAL DA SOCIEDADE BRASILEIRA DE ZOOTECNIA, 40., 2003, Santa Maria, RS. Anais... Santa Maria: SBZ, 2003. CD-ROM.

CARDOSO, G.C.; GARCIA, R.; SOUZA, A.L. et al. Desempenho de novilhos Simental alimentados com silagem de sorgo, cana-deaçúcar e palhada de arroz tratada ou não com amônia anidra. Rev. Bras. Zootec., v.33, supl.2, p.2132-2139, 2004. 
CARVALHO, G.G.P.; PIRES, A.J.V.; VELOSO, C.M. et al. Valor nutritivo do bagaço de cana-de-açúcar amonizado com quatro doses de ureia. Pesq. Agropec. Bras., v.41, p.125-132, 2006.

CAVALI, J. Cana-de-açúcar ensilada com óxido de cálcio, capim-elefante ou inoculante bacteriano. 2006. 60f. Dissertação (Mestrado) Universidade Federal de Viçosa, Viçosa.

FERREIRA， D.A.; GONÇALVES， L.C.; MOLINA, L.R. et al. Características de fermentação da silagem de cana-de-açúcar tratada com ureia, zeólita, inoculante bacteriano e inoculante bacteriano/enzimático. Arq. Bras. Med. Vet. Zootec., v.59, p.423-433, 2007.

MARTINES, E. Processo de hidrólise da cana para alimentação de vacas em lactação, Curitiba: Instituto de Tecnologia do Paraná - TECPAR, 2006. Disponível em: (http://www.sbrt.ibict.br). Acessado em: 20 set. 2007.

PIRES, A.J.V.; GARCIA, R.; CECON, P.R. et al. Amonização da quirera de milho com alta umidade. Rev. Bras. Zootec., v.28, p.1186-1193, 1999.
PIRES, A.J.V.; GARCIA, R.; VALADARES FILHO, S.C. et al. Novilhas alimentadas com bagaço de cana-de-açúcar tratado com amônia anidra e ou sulfeto de sódio. Rev. Bras. Zootec., v.33, p.1078-1085, 2004.

PIRES, A.J.V.; REIS, R.A.; CARVALHO, G.G.P. et al. Bagaço de cana tratado com hidróxido de sódio. Rev. Bras. Zootec., v.35, p.953-957, 2006.

PRADO, I.N.; MOREIRA, F.B. Suplementação de bovinos no pasto e alimentos usados na bovinocultura. Maringá: UEM, 2002. 162p.

SARMENTO, P.; GARCIA, R.; PIRES, A.J.V. et al. Tratamento do bagaço de cana-de-açúcar com ureia. Rev. Bras. Zootec., v.28, p.12031208, 1999.

SILVA, D.J., QUEIROZ, A.C. Análise de alimentos: métodos químicos e biológicos. Viçosa: UFV, 2002. 235p.

SISTEMA de análises estatísticas e genéticas SAEG. Viçosa: UFV, 2001, 301p. 